\title{
SELECTION AMONG INNOVATIVE PROJECT PROPOSALS USING A HESITANT FUZZY MULTIPLE CRITERIA DECISION MAKING METHOD
}

\author{
DOI: $10.17261 /$ Pressacademia.2017.449
}

JEFA-V.4-ISS.2-2017(14)-p.192-200

\author{
Basar Oztaysi ${ }^{1}$, Sezi Cevik Onar ${ }^{2}$, Cengiz Kahraman ${ }^{3}$ \\ ${ }^{1}$ Istanbul Technical University, Industrial Engineering Department, Istanbul, Turkey. oztaysib@itu.edu.tr \\ ${ }^{2}$ Istanbul Technical University, Industrial Engineering Department, Istanbul, Turkey. cevikse@itu.edu.tr \\ ${ }^{3}$ Istanbul Technical University, Industrial Engineering Department, Istanbul, Turkey. kahramanc@itu.edu.tr
}

\section{To cite this document}

Oztaysi, B., S.C. Onar and C. Kahraman, (2017). Selection amaong innovative project proposals using a hesitant fuzzy multiple criteria decision making method. Journal of Economics, Finance and Accounting (JEFA), V.4, Iss.2, p.192-200.

Permemant link to this document: http://doi.org/10.17261/Pressacademia.2017.449

Copyright: Published by PressAcademia and limited licenced re-use rights only.

\begin{abstract}
Purpose- In recent decades, innovation and desearch and development (R\&D) has been the key component for growth and economic competitiveness for companies and countries.

Methodology- Since innovation Project require considerable funds and contain risk, it is important to evaluate their potantial performance and return on investment to make proper decision.

Findings- The objective of this study is to develop a decision model for innovative Project selection using multicriteria decision making model (MCDM) and Hesitant Fuzzy sets. By using MCDM approach, various perspectives on project evaluation can be integrated into decision making model.

Conclusion- Employing hesitant fuzzy sets enable a better representation of decision makers' inguistic evaluations and thus provide better results.
\end{abstract}

Keywords: Innovative projects, hesitant fuzzy sets, multiple criteria, decision making.

JEL Codes: D82, M19, O32

\section{INTRODUCTION}

In today's competitive, globalized markets, generating competitive advantage through the continuous introduction of new products, services and processes has become a vital challenge (Meuer et al., 2015). OECD (2015) claim that innovation supports economic growth and can play a critical for providnig sustainable growth. However, still there is no structured methodology for innovation activities, studies show that upto $90 \%$ of innovative initiations fail to realize its goals depending on category (Gourville, 2006). Thus, innovation projects are evaluated as uncertain attempts to long term success. This leads the problem of innovative project assessment and selection.

After their review on quantitative models used for R\&D project selection Heidenberger and Stummer (1999) propose five groups: first group is benefit measurement methods which use mainly economic models for project selection. Second group is mathematical programming which use linear and non-linear models for project selection. Third group is artificial intelligence which use expert systems and fuzzy sets. Fourth group is simulation and heuristic approaches. The last group is decision theory which uses decision analysis and multicriteria decision making (MCDM) approach in project selection. This study can be classified in the last group since it uses MCDM approach. MCDM deals with problems that takes place in discrete decision space and the alternatives are predetermined. Innovative project selection can be modeled as a MCDM problem since it brings the flexibility to handle various conflicting criteria in the decision model.MCDM problems have 
already been recenty used in both innovative project selection studies (Oztaysi et al. 2017, Morton et al., 2016) as well as other specific project selection Read et al., 2017, Rouhani, 2017, Oztaysi et al. 2016, Stojcetovic et al. 2016, Oztaysi, 2015, Mousavi et al. 2015)

In the conventional MCDM methods, decision makers' evaluations are the key for problem definition and they are generally represented using numerical numbers. However in many real world problems collecting and using numerical values may be unrealistic. In order to deal with these kind of situations fuzzy set theory is developed (Zadeh, 1965). Using fuzzy sets, imprecision and uncertainty can be better handled in decision making problems. In set theory an item either blongs to a set or not, fuzzy set theory extend this with the concept of membership degree. Membership degree gets a value between 0 and 1 , and show the degree of membership to a set. In addition to ordinary fuzzy sets, new extensions of fuzzy sets are proposed. The term Hesitant fuzzy set (HFS) is proposed by Torra (2010) for cases where the membership value of an item to a specific set can take more than one value. With this unique property HFS enables to model hesitancy of decision makers into the decision model.

The originality of this paper comes from using hessitant fuzzy sets in innovative project selection problem for the first time. The rest of the paper is as follows. Section 2 presents a brief literature review of innovative project selection studies. Section 3 provides the decision model, steps of the methodology and numerical application. The results of the methodology is discussed in Section 4 . In the last section, suggestions on future studies are given.

\section{LITERATURE REVIEW}

Innovation and R\&D has been in close connection since R\&D is one of the main sources of sucessfull innovation initiatives. A brief survey on Scopus database containing the R\&D, innovation, and project selection revelas that the academic studies on the topic goes back to 1962. Since then, a increasing trend can be observed, especially after 2000 (Figure 1.).

In the recent years, studies on the topic has increased. Liu et al. (2017) propose an R\&D project selection based on evidential reasoning rule based model integrating experts' weights and reliabilities into the decision process. In another study, Caglar \& Gurel (2017) focus on project portfolio selection considering cancellation probabilities, using mixed-integer linear programming and dynamic programming algorithm. Karaveg et al. (2016) investigate the criteria of R\&D commercialization capability after applying a survey on enterpreneurs and researchers. Mohagheghi et al. (2015) propose a model using interval type-2 fuzzy sets to assessing R\&D projects. Using fuzzy sets and a new proposed, risk-return index the evaluation is first introduced. This model includes a new risk-return index. The model is also extended in project portfolio selection and a case study is applied to energy industry.

Heydari et al. (2016) integrate project portfolio selection problem with scheduling. The proposed model is constructed to form bi-objective non-linear problem. Ater, the authors use goal programming technique to solve the model to find the optimal portfolio and their schedule. Cluze et al. (2016) propose a novel process based on the eco-design strategy. The first step of the process is generating potential eco-innovative R\&D projects, then the proposed projects are analyzed and assessed using multicriteria approach. They are then analyzed and assessed using an appropriate multi-criteria grid Karasakal and Aker (2015) propose a R\&D project ranking method using data envelopment analysis (DEA) and Interval Analytic Hierarchy Process. Interval Analytic Hierarchy Process is used to obtain the weights of the criteria. The authors also propose treshold estimation and assignment models for sorting the alternative projects.

Figure 1: Academic studies on innovative project selection

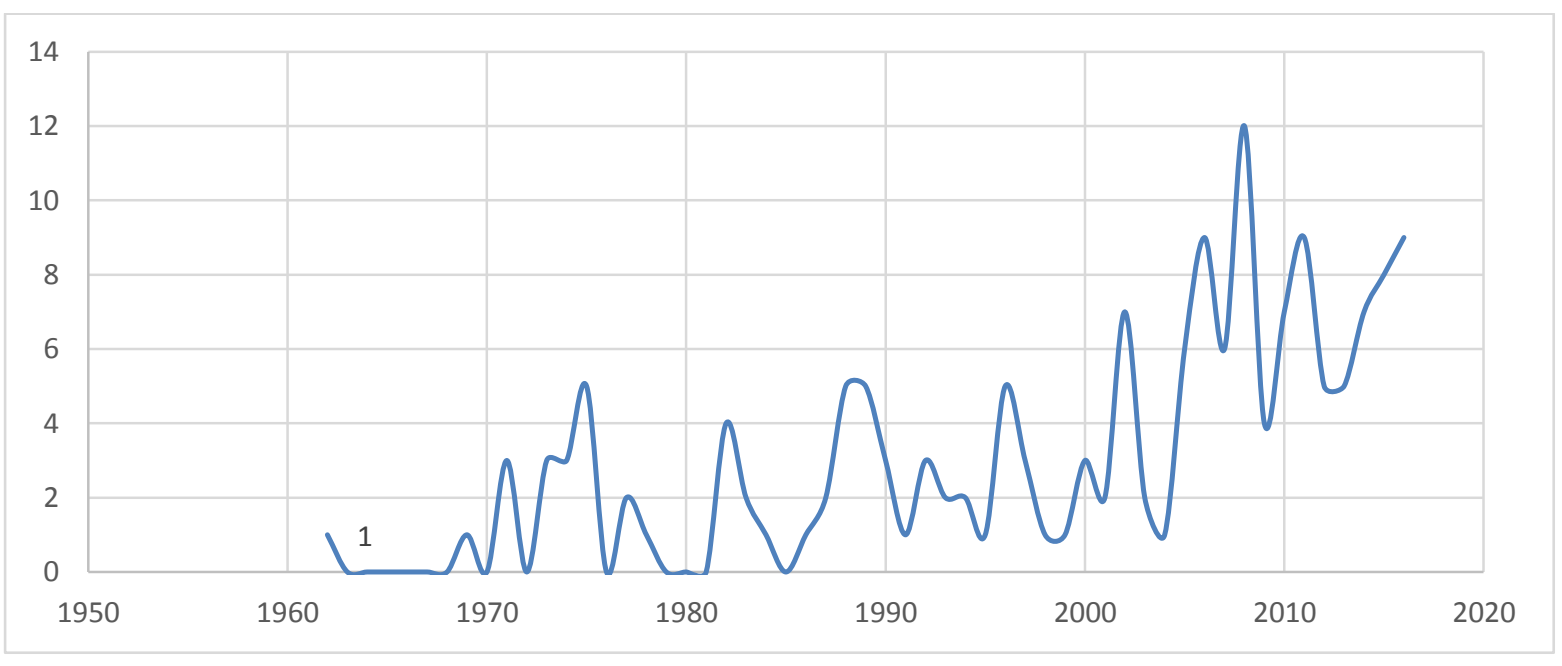


Hassanzadeh et al. (2014) propose using multiobjective binary integer programming model for R\&D project portfolio selection. The authors construct the model with uncertain constraints and objective functions. In the study, robust optimization is used to handle uncertainty and while and an interactive procedure is eployed for making tradeoffs among the multiple objectives. Silva et al (2014) proposes a novel hybrid process analytics approach to decompose the complex reviewer assignment for R\&D projects. The authors apply data-driven decision models with process analytics with the aim of achieving high operational efficiencies and high-quality assignment. Binneman and Steyn (2014) introduce an appropriate project selection criteria and gate review-point criteria for innovative project selection. The authors obtain the criteria as a resut of Delphi survey with seven experts. The resulting criteria contains fourteen selection criteria with their weight and forty relevant gate reviewing criteria. Güemes-Castorena and Uscanga-Castillo (2014) focus project selection problem of technology transfer offices based on expert experiences, feedbacks of applicants and evaluators to identify the relevance of the evaluation tool as well as to improve the performance and its impact. The paper also comprise the problems associated with applying the tool and interpreting the results. Zhao et al. (2012) propose using three main criteria, namely technical capability, satisfactory degree of project benefit and the crossing similarity, to evaluate alternative R\&D projects. The authors also propose three different fuzzy approaches to quantify these indicators. In the study, a multi-objective trade-off model is constructed and solved using heurtics.

\section{DATA AND METHODOLOGY}

\subsection{Hesitant Fuzzy Sets}

Hesitant Fuzzy Sets (HFSs) are introduced by (Torra, 2010) to deal with cases where membership degree of an element cannot be determined, or different experts define different values. In such cases HFSs can handle the situation without any loss of information.

Let $X$ be a fixed set, a hesitant fuzzy set (HFS) on $X$ is in terms of a function that when applied to $X$ returns a subset of $[0,1]$ (Torra,2010). Mathematical expression for HFS is as follows:

$E=\left\{<x, h_{E}(x)>\mid x \in X\right\}$,

Here, $h_{E}(x)$ is a set of some values in [0,1], denoting the possible membership degrees of the element $x \in X$ to the set.

The basic set operations and arithmetic operations on hesistant fuzzy sets are defined by Zhang and Wei, (2013) as follows:

$h^{\lambda}=\cup_{\gamma \in h}\left\{\gamma^{\lambda}\right\}$

$\lambda h=\cup_{\gamma \in h}\left\{1-(1-\gamma)^{\lambda}\right\} ;$

$h_{1} \cup h_{2}=\cup_{\gamma_{1} \in h_{1}, \gamma_{2} \in h_{2}}, \max \left\{\gamma_{1}, \gamma_{2}\right\}$;

$h_{1} \cap h_{2}=\cup_{\gamma_{1} \in h_{1}, \gamma_{2} \in h_{2}}, \min \left\{\gamma_{1}, \gamma_{2}\right\}$;

$h_{1} \oplus h_{2}=U_{\gamma_{1} \in h_{1}, \gamma_{2} \in h_{2}},\left\{\gamma_{1}+\gamma_{2}-\gamma_{1} \gamma_{2}\right\}$;

$h_{1} \otimes h_{2}=\cup_{\gamma_{1} \in h_{1}, \gamma_{2} \in h_{2}},\left\{\gamma_{1} \gamma_{2}\right\}$;

Hesitant fuzzy sets are has the potential to represent inguistic variables. For this purpose, hesitant fuzzy linguistic term sets (HFLTS) are introduced by Rodríguez et al. (2012). When experts or decision makers cannot agree on a single linguistic term, they need to represent the hesitancy into the decision model. HFLTSs offer flexibility to elicit comparative linguistic expressions by using context-free grammars that formalize the generation of flexible linguistic expressions.

Ordered weighted average (OWA) operator of dimension $\mathrm{n}$ provide a mapping OWA: $R^{n} \rightarrow R$, so that

$O W A\left(a_{1}, a_{2}, \ldots, a_{n}\right)=\sum_{j=1}^{n} w_{j} b_{j}$

where $b_{j}$ is the $j$ th largest of the aggregated arguments $a_{1}, a_{2}, \ldots, a_{n}$, and $W=\left(w_{1}, w_{2}, \ldots, w_{n}\right)^{T}$ is the associated weighting vector satisfying $\mathrm{w}_{\mathrm{i}} \in[0,1], \mathrm{i}=1,2, \ldots, \mathrm{n}$ and $\sum_{\mathrm{i}=1}^{\mathrm{n}} \mathrm{w}_{\mathrm{i}}=1$.

A triangular fuzzy membership function $\tilde{A}=(\mathrm{a}, \mathrm{b}, \mathrm{c})$ is used as the representation of the comparative linguistic expressions based on HFLTS HS, the definition domain of $\tilde{A}$ should be the same as the linguistic terms $\left\{\mathrm{s}_{\mathrm{i}}, \ldots, \mathrm{s}_{\mathrm{j}}\right\} \in \mathrm{H}_{\mathrm{S}}$. The min and the max operators are used to compute a and c.

$$
\mathrm{s}_{\mathrm{i}}=\left(a_{l}^{i}, a_{m}^{i}, a_{u}^{i}\right)
$$

$a=\min \left\{a_{l}^{i}, a_{m}^{i}, a_{l}^{i+1}, \ldots, a_{m}^{j}, a_{u}^{j}\right\}=a_{l}^{i}$

$c=\max \left\{a_{l}^{i}, a_{m}^{i}, a_{l}^{i+1}, \ldots, a_{m}^{j}, a_{u}^{j}\right\}=a_{u}^{j}$ 
The remaining elements $a_{m}^{i}, a_{m}^{i+1}, \ldots, a_{m}^{j} \in T$ should contribute to the computation of the parameter $\mathrm{b}$. The aggregation operator OWA will be used to aggregate them:

$b=O W A_{W^{s}}\left(a_{m}^{i}, a_{m}^{i+1}, \ldots, a_{m}^{j}\right)$

\subsection{Hesitant Fuzzy AHP}

Based on the definitions given in the previous sub-section, Analytic Hierarchy Process method is extended to process hesitanat fuzzy sets (Oztaysi et al. 2015, Kahraman et. al, 2016). The steps of the Hesitant Fuzzy AHP method are given in the following:

Step 1. Pairwise comparison matrices are formed based on the decision hierarchy and decision makers fill the matrices using linguistic terms given in Table 1.

Step 2. The linguistic terms are transform fuzzy nubers using Table 1.

Table 1: Linguistic Scale for Hesitant Fuzzy AHP

\begin{tabular}{|c|c|c|c|}
\hline & Linguistic Term & Abb. & $\begin{array}{l}\text { Triangular } \\
\text { Number }\end{array}$ \\
\hline $\mathrm{S}_{10}$ & $\begin{array}{l}\text { Absolutely } \\
\text { Importance }\end{array}$ & $(\mathrm{AHI})$ & $(7,9,9)$ \\
\hline$s_{9}$ & Very High Importance & (VHI) & $(5,7,9)$ \\
\hline $\mathrm{S}_{8}$ & $\begin{array}{l}\text { Essentially } \\
\text { Importance }\end{array}$ & (ESHI) & $(3,5,7)$ \\
\hline $\mathrm{S}_{7}$ & Weakly High Importance & (WHI) & $(1,3,5)$ \\
\hline$s_{6}$ & Equally High Importance & (EHI) & $(1,1,3)$ \\
\hline$S_{5}$ & Exactly Equal & (EE) & $(1,1,1)$ \\
\hline $\mathrm{s}_{4}$ & Equally Low Importance & (ELI) & $(0.33,1,1)$ \\
\hline $\mathrm{s}_{3}$ & Weakly Low Importance & (WLI) & $(0.2,0.33,1)$ \\
\hline $\mathrm{S}_{2}$ & $\begin{array}{l}\text { Essentially } \\
\text { Importance }\end{array}$ & (ESLI) & $(0.14,0.2,0.33)$ \\
\hline$s_{1}$ & Very Low Importance & (VLI) & $(0.11,0.14,0.2)$ \\
\hline $\mathrm{s}_{0}$ & $\begin{array}{l}\text { Absolutely } \\
\text { Importance }\end{array}$ & (ALI) & $(0.11,0.11,0.14)$ \\
\hline
\end{tabular}

Experts' compromised evaluations may also be composed of the linked linguistic evaluations such as between EHI and WHI, or between ESLI and WLI.

Let $\tilde{A}$ be a pairwise comparison matrix and $\tilde{a}_{i j}$ be its element. In cases where the decision makers cannot agree on the same linguistic term then $\tilde{a}_{i j}$ is defined as linked linguistic evaluation such as between EHI and WHI, or between ESLI and WLI. The pairwise comparison matrix is given by;

$\tilde{A}=\left|\begin{array}{cccc}\tilde{a}_{11} & \tilde{a}_{12} & \ldots & \tilde{a}_{1 n} \\ \tilde{a}_{21} & \tilde{a}_{22} & \ldots & \tilde{a}_{2 n} \\ \vdots & \vdots & \ldots & \vdots \\ \tilde{a}_{n 1} & \tilde{a}_{n 2} & \ldots & \tilde{a}_{n n}\end{array}\right|$

where $\left(\tilde{a}_{i j}\right)$ represents the compromised fuzzy set evaluation on comparison of ith element to jth element. 
Step 2. The consistency of compromised fuzzy pairwise comparison matrix is cheked. If the pairwise comparisons are not consistent, experts must reevaluate the compromised pairwise comparison matrix.

Step 3: The linked evaluations are transformed into numerical values using envelope method by Liu and Rodriguez (2014). The result of this operation is in the form of trapezoidal fuzzy numbers. In the following the operations are summarized.

Assume the experts' compromised evaluations vary between two terms i.e. $s_{i}$ and $s_{j}$. Then $s_{0} \leq s_{i}<s_{j} \leq s_{10}$. The parameters $a$ and $d$ of the trapezoidal fuzzy membership function ( $a, b, c, d)$ are computed as

$$
\begin{aligned}
& a=\min \left\{a_{l}^{i}, a_{m}^{i}, a_{l}^{i+1}, \ldots, a_{m}^{j}, a_{u}^{j}\right\}=a_{l}^{i} \\
& d=\max \left\{a_{l}^{i}, a_{m}^{i}, a_{l}^{i+1}, \ldots, a_{m}^{j}, a_{u}^{j}\right\}=a_{u}^{j}
\end{aligned}
$$

$b=\left\{\begin{array}{c}a_{m}^{i}, \text { if } i+1=j \\ o W A_{w^{2}}\left(a_{m}^{i}, \ldots, a_{m}^{\frac{i+j}{2}}\right), \quad \text { if } i+j \text { is even } \\ o W A_{w^{2}}\left(a_{m}^{i}, \ldots, a_{m}^{\frac{i+j-1}{2}}\right), \quad \text { if } i+j \text { is odd }\end{array}\right.$

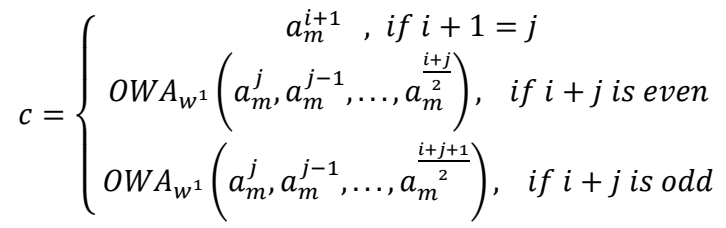

OWA weights required by the formula are calculated as defined in Filev and Yager (1998).

Step 4: numerical pairwise comparison matrix $(\tilde{C})$ is formed.

$$
\tilde{C}=\left|\begin{array}{cccc}
(1,1,1,1) & \tilde{c}_{12} & \ldots & \tilde{c}_{1 n} \\
\tilde{c}_{21} & (1,1,1,1) & \ldots & \tilde{c}_{2 n} \\
\vdots & \vdots & \vdots: \vdots & \vdots \\
\tilde{c}_{n 1} & \tilde{c}_{n 2} & \cdots & (1,1,1,1)
\end{array}\right|
$$

$$
\begin{aligned}
& \text { where } \tilde{c}_{i j}=\left(c_{i j_{l}}, c_{i j_{m 1}}, c_{i j_{m 2}}, c_{i j_{u}}\right) \text { and } \\
& \tilde{c}_{j i}=\left(\frac{1}{c_{i j_{u}}}, \frac{1}{c_{i j_{m 2}}}, \frac{1}{c_{i j_{m 1}}}, \frac{1}{c_{i j_{l}}}\right)
\end{aligned}
$$

Step 5: Fuzzy geometric mean for each row $\left(\tilde{r}_{i}\right)$ is computed using Eq. 17.

$$
\tilde{r}_{i}=\left(\tilde{c}_{i 1} \otimes \tilde{c}_{i 2} \ldots \otimes \tilde{c}_{i n}\right)^{1 / n}
$$

Step 6: The fuzzy weight $\left(\widetilde{w}_{i}\right)$ of each attribute (or alternative) is calculated using $\left(\tilde{r}_{i}\right)$ values as follows:

$$
\widetilde{w}_{i}=\tilde{r}_{i} \otimes\left(\tilde{r}_{1} \oplus \tilde{r}_{2} \ldots \oplus \tilde{r}_{n}\right)^{-1}
$$

Step 7: In order to find the crisp results the trapezoidal fuzzy numbers are defuzzified using Eq. 19.

$$
D=\frac{c_{l}+2 c_{m 1}+2 c_{m 2}+c_{u}}{6}
$$

Step 8: The next step is to calculate the performance scores of each alternative. To this end, the steps $1-7$ are repeated for each pairwise comparison matrix. The overall weights and alternative priorities are calculated by multiplying the local value with the parent's weights.

Step 9: The alternative with the highest defuzzified value is selected as the best alternative. 


\section{FINDINGS AND DISCUSSIONS}

In this sub section, criteria for innovative project selection is introduced, then numerical application.

\subsection{Criteria for Innovative Project Selection}

The hierarchy for innovative project selection has four criteria and twelve subcriteria as shown in Figure 2.

Figure 2: Hierarchy and Crieria for Innovative Project Selection

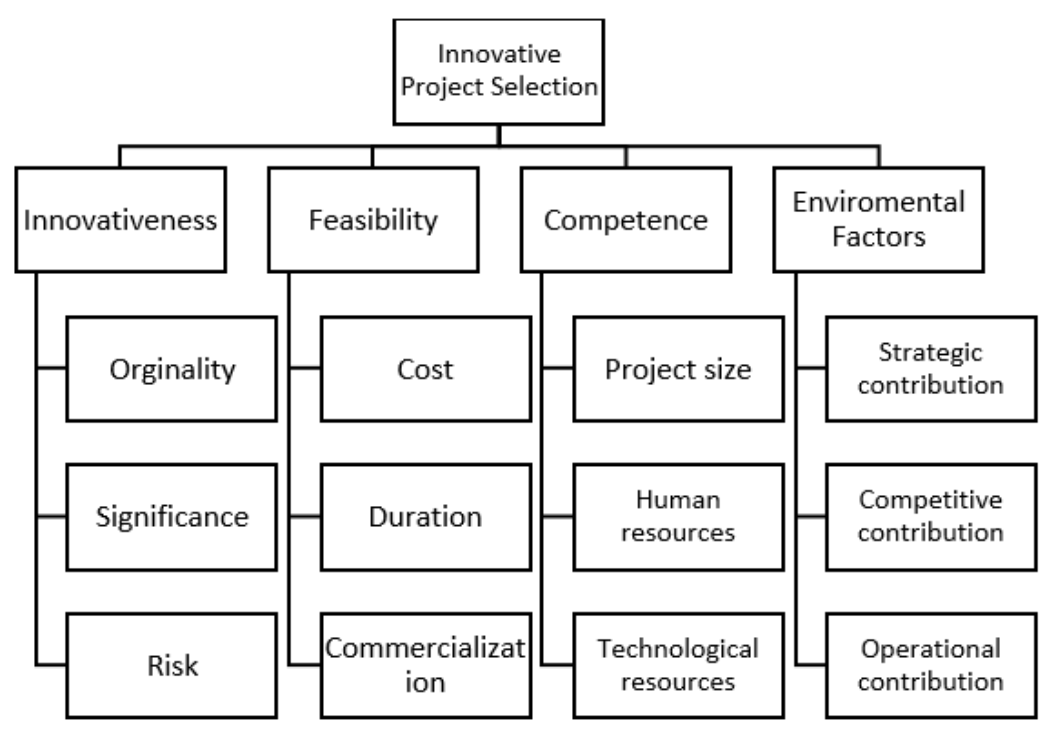

The first criterion of the decision model is Innovativeness which defines the originality of the project, significance of the potential outcome and risk of the projet. The second criterion is Feasibility which is analyzed by total cost of the project, planned duration of the project and possibility of commercialization. The third criterion is Competence which deals with the integration of the project with the company. It contains sub-criteria such as project size, human resources and technological resources. The last criterion is Enviromental Factors which focus on the contribution of the potential outcome to company's strategies, competitive power and operations.

\subsection{Results of Hesitant AHP}

The application of the method starts with comparing the criteria with respect to the main goal. The decision makers compared each criterion with others. Table 2 shows the results of the comparison by the decision making team.

Table 2: Pairwise comparison of criteria with respect to the goal

\begin{tabular}{l|llll}
\hline & Innovativeness & Feasibility & Competence & Environmental \\
\hline Innovativeness & EE & $\begin{array}{l}\text { Between WHI } \\
\text { and ESHI }\end{array}$ & EE & $\begin{array}{l}\text { Between EE } \\
\text { and EHI }\end{array}$ \\
Feasibility & EE & EE & $\begin{array}{l}\text { Between WLI } \\
\text { and ELI }\end{array}$ \\
Competence & EE & ELI \\
Environmental & & & EE \\
\hline
\end{tabular}

After applying step 2 and step 3, numerical pairwise comparison matrix is obtained as shown in Table 3. 
Table 3: Numerical Pairwise Comparison Matrix with Respect to the Goal

\begin{tabular}{l|llll}
\hline & Innovativeness & Feasibility & Competence & Environmental \\
\hline Innovativeness & $(1,1,1,1)$ & $(1,3,5,7)$ & $(1,1,1,1)$ & $(1,1,1,3)$ \\
Feasibility & $(0.143,0.2,0.333,1)$ & $(1,1,1,1)$ & $(1,1,1,1)$ & $(0.2,0.333,1,1)$ \\
Competence & $(1,1,1,1)$ & $(1,1,1,1)$ & $(1,1,1,1)$ & $(0.333,1,1,1)$ \\
Environmental & $(0.333,1,1,1)$ & $(1,1,3,5)$ & $(1,1,1,3)$ & $(1,1,1,1)$ \\
\hline
\end{tabular}

Then geometric means are calculated, later hesitant fuzzt weights are obtained and these weights are defuzzified to findthe crisp weights. These values are shown in Table 4.

Table 4: Geometric Means and Weights

\begin{tabular}{lrrr}
\hline & Geometric Means & Hesitant Fuzzy Weights & Crisp Weights \\
\hline Innovativeness & $(1,1.316,1.495,2.140)$ & $(0.164,0.288,0.391,0.73)$ & 0.342 \\
Feasibility & $(0.411,0.508,0.759,1)$ & $(0.067,0.111,0.199,0.341)$ & 0.156 \\
Competence & $(0.759,1,1,1)$ & $(0.124,0.219,0.261,0.341)$ & 0.206 \\
Environmental & $(0.759,1,1.316,1.967)$ & $(0.124,0.219,0.344,0.671)$ & 0.296 \\
\hline
\end{tabular}

The same steps are later applied to subcriteria. In other words, each sub-criterion of a criterion is pairwise compared with the other subcriteria under same criterion. Table 5 shows the results of the sub-criteria comparisons. Local weights are the weights of the sub-criterion under the related criterion, and global weights show overall weight of the subcriterion.

Table 5: Weights of the Sub-Criteria

\begin{tabular}{lrcc}
\hline Sub-Criterion & Hessitan Fuzzy Weight & Local Weight & Global Weight \\
\hline Orginality (SC1) & $(0.162,0.332,0.916,1)$ & 0.475 & 0.162 \\
Significance (SC2) & $(0.049,0.093,0.258,0.547)$ & 0.187 & 0.064 \\
Risk (SC3) & $(0.085,0.194,0.441,1)$ & 0.339 & 0.116 \\
Cost (SC4) & $(0.129,0.377,0.489,0.794)$ & 0.394 & 0.061 \\
Duration (SC5) & $(0.051,0.089,0.116,0.288)$ & 0.12 & 0.019 \\
Commercialization (SC6) & $(0.269,0.447,0.489,1)$ & 0.486 & 0.076 \\
Project Size (SC7) & $(0.151,0.291,0.371,0.732)$ & 0.321 & 0.066 \\
Human Resources (SC8) & $(0.151,0.291,0.535,0.867)$ & 0.383 & 0.079 \\
Technological Sources (SC9) & $(0.127,0.201,0.371,0.732)$ & 0.297 & 0.061 \\
Project Size (SC10) & $(0.151,0.291,0.371,0.732)$ & 0.321 & 0.095 \\
Human Resources (SC11) & $(0.151,0.291,0.535,0.867)$ & 0.383 & 0.113 \\
Technological Sources (SC12) & $(0.127,0.201,0.371,0.732)$ & 0.297 & 0.088 \\
\hline
\end{tabular}

The next step is to form pairwise comparisons for the alternatives with respect to each criterion. To this end twelve pairwise comparison matrices are formed and filled by the decision makers. The results are shown in Table 6.

The last step is to find the weighted sum of alternative scores to find the overall priorities.

Table 6: Results of Evaluations of the Alternatives

\begin{tabular}{llllllllllllll}
\hline & SC1 & SC2 & SC3 & SC4 & SC5 & SC6 & SC7 & SC8 & SC9 & SC10 & SC11 & SC12 & Wght. Sum \\
\hline Weights & 0.162 & 0.064 & 0.116 & 0.061 & 0.019 & 0.076 & 0.066 & 0.079 & 0.061 & 0.095 & 0.113 & 0.088 & \\
Alt.1 & 0.320 & 0.219 & 0.409 & 0.320 & 0.233 & 0.313 & 0.354 & 0.198 & 0.385 & 0.388 & 0.219 & 0.386 & 0.319 \\
Alt.2 & 0.226 & 0.262 & 0.143 & 0.226 & 0.267 & 0.221 & 0.201 & 0.254 & 0.173 & 0.205 & 0.262 & 0.203 & 0.216 \\
Alt.3 & 0.219 & 0.228 & 0.206 & 0.219 & 0.267 & 0.279 & 0.214 & 0.287 & 0.207 & 0.209 & 0.228 & 0.241 & 0.230 \\
Alt.4 & 0.235 & 0.292 & 0.243 & 0.235 & 0.233 & 0.187 & 0.231 & 0.261 & 0.234 & 0.199 & 0.292 & 0.169 & 0.235 \\
\hline
\end{tabular}


The results reveal that Alternative 1 has the highest priority and it is followed by Alternative 4, Alternative 3 and Alternative 2 .

\section{CONCLUSION}

Innovation projects are the source of economic growth but they require considerable investments and bear lots of risks. Thus selection of the right project is very important for companies. In this paper innovative Project project selection is modeled as a MCDM problem and hesitant AHP is applied in a numerical case study.

In the case study a decision model with four criteria and twelve sub-criteria and three alternatives is built. The criteria are determined after a literature survey and with the help of decision making team's comments. The results reveal that the most important criterion is Innovativeness which is followed by Environmental Factors. Among the sub Criteria, the most important ones are found to be Orginality, Risk and Human Resources. Finally, Alternative 4 is selected as the best alternative.

In thisstudy, by using hesitant fuzzy sets, the hesitancy of the decision makers are integrated into the calculations, in tother words, evaluations of the decision makers are better represented in the model, without information loss. One of the limitation of the study is that, as the number of alternatives increase, the number of pairwise comparisons increase exponantially. For the future studies, the decision model can be extended with TOPSIS or VIKOR Method so that the results are found based on idela solutions, instead of pairwise comparisons. Another suggestion for further studies is to extend the method to work with incomlete pairwise comparisons.

\section{REFERENCES}

Meuer, J., Rupietta, C., Backes-Gellner, U. 2015. “Layers of co-existing innovation systems”. Research Policy, 44(4), 888-910.

Gourville, J. 2006, "Eager seller and stony buyers: understanding the psychology of new-product adaptation”. Harvard Business Review, 84(6), 98-106.

Mohagheghi V., Mousavi S.M., Siadat A. 2015, "A new approach in considering vagueness and lack of knowledge for selecting sustainable portfolio of production projects" In: IEEE conference on industrial engineering and engineering management (IEEM), pp 1732-1736.

Heydari, T., Seyed Hosseini, S.-M., Makui, A. 2016, “Developing and solving an one-zero non-linear goal programming model to R and D portfolio project selection with interactions between projects", International Business Management, 10(19), pp. 4516-4521.

OECD, 2015. The OECD Innovation Strategy - 2015, http://www.oecd.org/innovation/innovation-imperative.htm, last accessed: 02.03.2017.

Heidenberger K. Stummer C. 1999, "Research and development project selection and resource allocation: a review of quantitative modelling approaches", International Jurnal of Management Reviews, Volume 1, Issue 2, Pages 197-224.

Oztaysi, B., Onar, S.C., Goztepe, K., Kahraman C. 2017 "Evaluation of research proposals for grant funding using interval-valued intuitionistic fuzzy sets", Soft Computing, Volume 21, Issue 5, pp 1203-1218.

Morton A., Keiser J.M., Salo A. 2016. "Multicriteria Portfolio Decision Analysis for Project Selection, Multiple Criteria Decision Analysis", Volume 233 of the series International Series in Operations Research \& Management Science pp 1269-1298.

Read L., Madani K., Mokhtari S., Hanks C. 2017, "Stakeholder-driven multi-attribute analysis for energy project selection under uncertainty", Energy, Volume 119, Pages 744-753.

Rouhani S.2017 "A fuzzy superiority and inferiority ranking based approach for IT service management software selection", Kybernetes, Vol. 46 Issue: 4, pp.728-746, (2017).

Oztaysi B., Cevik Onar B., Kahraman C. 2016 "Fuzzy multicriteria prioritization of Urban transformation projects for Istanbul”, Journal of Int. \& Fuzzy Systems 30 (4), 2459-2474i

Stojcetovic B., Nikolic D., Velinov V., Bogdanovic D. 2016, "Application of integrated strengths, weaknesses, opportunities, and threats and analytic hierarchy process methodology to renewable energy project selection in Serbia", Journal of Renewable and Sustainable Energy, 8.

Oztaysi, B. 2015. “A Group Decision Making Approach Using Interval Type-2 Fuzzy AHP for Enterprise Information Systems Project Selection", Journal of Multiple-Valued Logic and Soft Computing, Volume: 24 Issue: 5-6 Pages: 475-500.

Mousavi, S. M., Vahdani, B., Hashemi, H., Ebrahimnejad, S. 2015. “An Artificial Intelligence Model-Based Locally Linear Neuro-Fuzzy for Construction Project Selection", Journal of Multiple-Valued Logic \& Soft Computing, Vol. 25 Issue 6, p589-604.

Zadeh L.A. 1965, "Fuzzy sets", Information and Control 8 (3) 338-353.

Torra V. 2010, “Hesitant fuzzy sets”, Inernational Journal of Intelligent Systems, Volume 25, Issue 6, Pages 529-539. 
Liu, F., Zhu, W.D., Chen, Y.W., Xu, D.L., Yang, J.B. 2017, “Evaluation, ranking and selection of R\&D projects by multiple experts: an evidential reasoning rule based approach", Scientometrics, pp. 1-19.

Çağlar, M., Gürel, S. 2017, “Public R\&D project portfolio selection problem with cancellations”, OR Spectrum,pp. 1-29

Karaveg, C., Thawesaengskulthai, N., Chandrachai, A. 2016, "R\&D commercialization capability criteria: implications for project selection", Journal of Management Development 35(3), pp. 304-325.

Mohagheghi, V., Mousavi, S.M., Vahdani, B., Shahriari, M.R. 2016, "R\&D project evaluation and project portfolio selection by a new interval type-2 fuzzy optimization approach", Neural Computing and Applications, pp. 1-20.

Heydari, T., Seyed Hosseini, S.M., Makui, A., 2016, "Developing and solving an one-zero non-linear goal programming model to R and D portfolio project selection with interactions between projects", International Business Management, 10(19), pp. 4516-4521.

Cluzel, F., Yannou, B., Millet, D., Leroy, Y. 2016. "Eco-ideation and eco-selection of R\&D projects portfolio in complex systems industries", Journal of Cleaner Production, 112, pp. 4329-4343.

Zhao, X., Yang, Y., Wu, G., Yang, J., Xue, X., 2012. “A dynamic and fuzzy modeling approach for multi-objective R \& D project portfolio selection", Journal of Convergence Information Technology, 7(1), pp. 36-44.

Zhang, N., and Wei G. 2013, Extension of VIKOR method for decision making problem based on hesitant fuzzy set, Applied Mathematical Modelling, 37(7), 4938-4947.

Rodriguez R.M., Martinez L. and Herrera F. 2012, "Hesitant Fuzzy linguistic term sets for decision making”, IEEE Transactions on Fuzzy Systems 20(1), 109-19.

Öztaysi B., Cevik Onar S., Boltürk E., Kahraman C., 2015, “Hesitant fuzzy analytic hierarchy process”, Fuzzy Systems (FUZZ-IEEE), 2015 IEEE International Conference on, 1-7

Kahraman C., Boltürk E., Cevik Onar S., Öztayşi B., 2016, “Multi-Attribute Warehouse Location Selection In Humanitarian Logistics Using Hesitant Fuzzy", International Journal of the Analytic Hierarchy Process 8 (2), 271-298.

Filev D., Yager R.R., 1998, “On the issue of obtaining OWA operator weights”, Fuzzy sets and systems 94 (2), 157-169.

Cluzel, F., Yannou, B., Millet, D., Leroy, Y. 2016, "Eco-ideation and eco-selection of R\&D projects portfolio in complex systems industries", Journal of Cleaner Production, 112, pp. 4329-4343.

Karasakal, E., Aker, P. 2015, "A multicriteria sorting approach based on data envelopment analysis for R\&D project selection problem", Omega.

Hassanzadeh, F., Nemati, H., Sun, M. 2014, "Robust optimization for interactive multiobjective programming with imprecise information applied to R\&D project portfolio selection", European Journal of Operational Research, 238(1), pp. 41-53.

Binneman, B., Steyn, H. 2014, "Criteria for selection and gate reviews of technology innovation projects", South African Journal of Industrial Engineering, 25(1), pp. 117-130

Güemes-Castorena, D., Uscanga-Castillo, G.I. 2014, "Evaluation tool for technological project selection in the early stage of innovation: Experiences from the development of the application in a technology transfer office", PICMET 2014 - Portland International Center for Management of Engineering and Technology, Proceedings: Infrastructure and Service Integration, pp. 2836-2842.

Silva, T., Jian, M., Chen, Y. 2014, “Process analytics approach for R\&D project selection", ACM Transactions on Management Information Systems, 5(4), 21 